\title{
Open Access Journal of Cardiology
}

\section{Current Treatments for Heart Failure}

\section{Caglar A and Nesligul Y*}

Faculty of Medicine Department of Cardiology, Kirikkale University, Turkey

*Corresponding author: Yildirim Nesligul, Faculty of Medicine, Department of Cardiology, Kirikkale University, Turkey, Email: nesligul2004@hotmail.com

\section{Mini Review}

Volume 2 Issue 2

Received Date: March 21, 2018

Published Date: April 09, 2018

\section{Abstract}

Heart failure (HF) is a chronic disease associated with significant mortality and morbidity. HF management contains of non pharmacologic, pharmacologic, and invasive strategies to limit and reverse its manifestations. Despite improvement in the treatment modalities, hospitalizations for HF remain frequent and mortality rates are still high. In this mini-review current treatment strategies are discussed.

Keywords: Heart failure treatment; Cardiac rehabilitation, Device therapy

Abbreviations: HF: Heart failure; HAPPY: Heart Failure Prevalence and Predictors in Turkey; HFrEF: HF with reduced ejection fraction; ACEI: Angiotensin Converting Enzyme Inhibitors; ARB: Angiotensin Receptor Blockers; ICD: Implanted Cardioverter-Defibrillator; VADs: Ventricular Assist Devices.

\section{Introduction}

Heart failure (HF) is one of the most important public health problems. It is also one of the most common causes of morbidity and mortality in the world. The worldwide prevalence of $\mathrm{HF}$ is estimated to be 23 million [1]. According to HAPPY (Heart Failure Prevalence and Predictors in Turkey) Study, the number of HF patients in Turkey is around 2 million [2]. Despite improvements in treatment strategies, mortality is very high due to the complex nature of the disease. The main goal of $\mathrm{HF}$ therapy is to reduce mortality and morbidity and also to improve the quality of life. Pharmacologic therapy, lifestyle modification, cardiac rehabilitation and device therapy are the cornerstones of treatment.

\section{Lifestyle Modification}

There is limited evidence that lifestyle modification increases quality of life. Even so it increases motivation for treatment. Lifestyle changes include the following: 1to stop smoking and taking recreational substances, 2- to avoid excessive fluid intake; fluid restriction of 1.5-2 L/day may be considered in patients with severe HF to relieve symptoms and congestion, 3- to gain healthy eating habits, 4 - to avoid excessive salt intake ( $>6 \mathrm{~g} /$ day), while the optimum sodium intake for patients with $\mathrm{HF}$ is not known. The 2013 ACC/AHA guidelines suggest that patients should consume less than 3 grams of sodium per day with regular exercise and avoidance of obesity [3].

\section{Cardiac Rehabilitation}

The recommended aerobic exercise prescription for HF patients typically does not differ greatly from those with other cardiac diseases, but aerobic interval training is highlighted as being particularly effective $[4,5]$. Aerobic activities include treadmill walking, cycling and upper body ergometry, dancing and swimming. A published study evaluated the effects of exercise in 37 patients with 


\section{Open Access Journal of Cardiology}

HF (New York Heart Association functional class III). After 12 weeks of exercise training; functional class, peak VO2 and left ventricle ejection fraction improved [6]. Exercise training in patients with compensated $\mathrm{HF}$ with reduced ejection fraction (HFrEF) reduces symptoms of depression, total and HF-related hospitalization $[7,8]$.

\section{Pharmacologic Therapy}

Pharmacologic therapy which reduce mortality in the treatment of systolic HF include angiotensin converting enzyme inhibitors (ACEI), angiotensin receptor blockers (ARB), beta blockers and mineralocorticoid receptor antagonists. Although digitals do not affect mortality, they were reported to reduce hospitalization [9]. There are new drugs entering HF guidelines as well as conventional therapy such as angiotensin receptor-neprilysin inhibitor (The combination of sacubitril/valsartan is called ARNI) and ivabradine (a selective sinus node inhibitor). ARNI is a new therapeutic class of agents acting on RAAS and neutral endopeptidase system. In a recent study, longterm effects of sacubitril / valsartan were investigated when compared to ACEI (enalapril) on morbidity and mortality in patients with symptomatic HFrEF. In this population, sacubitril / valsartan was superior to ACEI (enalapril 10), for reducing hospital admissions, cardiovascular mortality and overall mortality [10]. Ivabradine inhibits the $I_{\mathrm{f}}$ channel in sinus node and slows the heart rate. Ivabradine in HFrEF patients with left ventricle $\mathrm{EF} \leq 35 \%$ and in sinus rhythm with a resting heart rate $\geq 75 \mathrm{bpm}$, was shown to provide a survival benefit [11].

There are some drugs that were suggested to have benefit in relieving symptoms but do not affect mortality. These are combination of hydralazine and isosorbide dinitrate and intravenöz ferric carboxymaltose. The suggestions on the clinical utility of hydralazine and isosorbide combination comes from one relatively small trial conducted exclusively in men and before ACEIs or beta-blockers were used to treat HF [12]. The recently published CVD-REAL (Comparative Effectiveness of Cardiovascular Outcomes in New Users of SGLT-2 Inhibitors) Trial showed lower rates of hospitalization for $\mathrm{HF}$ and all-cause death in new users of sodium-glucose cotransporter-2 inhibitors as a group effect in patients with type II diabetes mellitus [13]. Intravenous administration of iron (ferric carboxymaltose) significantly improved exercise capacity and quality of life in patients with proven iron deficiency (ferritin $<20 \%$ ) and HF in the Ferric Carboxymaltose in Patients with Heart Failure and Iron Deficiency (FAIR-HF) Trial [14].

\section{Device Therapy}

An implanted cardioverter-defibrillator (ICD) is recommended (class Ia ) to reduce the risk of sudden death and all-cause mortality in patients who survive a ventricular arrhythmia causing haemodynamic instability [15]. Cardiac resynchronization therapy is recommended (class Ia) for symptomatic patients with HF in sinus rhythm with a QRS duration $\geq 150 \mathrm{msec}$ and left bundle branch block QRS morphology and with left ventricle $\mathrm{EF} \leq 35 \%$ despite optimal medical treatment in order to improve symptoms and reduce morbidity and mortality [16].

Intra-aortic balloon pump (IABP) can be used in patients with cardiogenic shock but there is no good evidence about benefit of IABP. Ventricular assist devices (VADs) are used for bridge to recovery, transplantation and lifetime or destination therapy in HF. VAD types are left ventricular assist device, right ventricular assist device and biventricular assist device.

\section{References}

1. McMurray JJ, Petrie MC, Murdoch DR, Davie AP (1998) Clinical epidemiology of heart failure: public and private health burden. Eur Heart J 19 (Suppl P): P9-P16.

2. Değertekin M, Erol C, Ergene O, Tokgözoğlu L, Aksoy M, et al . ( 2012) Türkiye'deki erişkin popülasyonda kalp yetersizliği prevelans ve prediktörleri : Heart failure prevalence and predictors in Turkey (HAPPY) çalışması. Turk Kardiyol Dern Ars 40(4): 298308.

3. Yancy CW, Jessup M, Bozkurt B, Butler J, Casey DE Jr, et al. (2013) 2013 ACCF/AHA guideline for the management of heart failure: executive summary: a report of the American College of Cardiology Foundation American Heart Association Task Force on practice guidelines. Circulation 128(16): 18101852.

4. Stone JA, Arthur HM, Suskin N (2009) Canadian Guidelines for Cardiac Rehabilitation and Cardiovascular Disease Prevention: Translating Knowledge into Action. 3rd (Edn.), Winnipeg, Canada: Canadian Association of Cardiac Rehabilitation.

5. Pavy B, Iliou MC, Verges-Patois B, Brion R, Monpère C, et al. (2012) French Society of Cardiology guidelines for cardiac rehabilitation in adults. Arch Cardiovasc Dis 105(5): 309-328. 


\section{Open Access Journal of Cardiology}

6. Erbs S, Hollriegel R, Linke A, Beck EB, Adams V, et al. (2010) Exercise training in patients with advanced chronic heart failure (NYHA IIIb) promotes restoration of peripheral vasomotor function, induction of endogenous regeneration, and improvement of left ventricular function. Circ Heart Fail 3(4): 486-494.

7. Tu RH, Zeng ZY, Zhong GQ, Wu WF, Lu YJ, et al. (2014) Effects of exercise training on depression in patients with heart failure: a systematic review and metaanalysis of randomized controlled trials. Eur J Heart Fail 16(7): 749-757.

8. Taylor RS, Sagar VA, Davies EJ, Briscoe S, Coats AJ, et al. (2014) Exercise-based rehabilitation for heart failure. Cochrane Database Syst Rev (4): CD003331.

9. (1997) The Digitalis Investigation Group: The effect of digoxin on mortality and morbidity in patients with heart failure. N Engl J Med 336(8): 525-533.

10. McMurray JJ, Packer M, Desai AS, Gong J, Lefkowitz MP, et al. (2014) Angiotensin-neprilysin inhibition versus enalapril in heart failure. $\mathrm{N}$ Engl J Med 371(11): 993-1004.

11. Bo"hm M, Borer J, Ford I, Gonzalez-Juanatey JR, Komajda M, et al. (2013) Heart rate at baseline influences the effect of ivabradine on cardiovascular outcomes in chronic heart failure: analysis from the SHIFT study. Clin Res Cardiol 102(1): 11-22.
12. Cohn JN, Archibald DG, Ziesche S, Franciosa JA, Harston WE, et al. (1986) Effect of vasodilator therapy on mortality in chronic congestive heart failure. N Engl J Med 314(24): 1547-1552.

13. Kosiborod M, Cavender MA, Fu AZ, Wilding JP, Khunti $\mathrm{K}$, et al. (2017) Lower risk of heart failure and death in patients initiated on sodium-glucose cotransporter-2 inhibitors versus other glucoselowering drugs: The CVD-REAL Study (Comparative Effectiveness of Cardiovascular Outcomes in New Users of Sodium-Glucose Cotransporter-2 Inhibitors). Circulation 136(3): 249-259.

14. Anker SD, Comin Colet J, Filippatos G, Willenheimer R, Dickstein $K$, et al. (2009) Ferric carboxymaltose in patients with heart failure and iron deficiency. N Engl J Med 361(25): 2436-2448.

15. Connolly SJ, Hallstrom AP, Cappato R, Schron EB, Kuck KH, et al. (2000) Meta-analysis of the implantable cardioverter defibrillator secondary prevention trials. AVID, CASH and CIDS studies. Antiarrhythmics vs Implantable Defibrillator study. Cardiac Arrest Study Hamburg. Canadian Implantable Defibrillator Study. Eur Heart J 21(24): 2071-2078.

16. Bristow MR, Saxon LA, Boehmer J, Krueger S, Kass DA, et al. (2004) Cardiac-resynchronization therapy with or without an implantable defibrillatorin advanced chronic heart failure. N Engl J Med 350(21): 21402150. 